\title{
Does a common pathophysiological basis exist in the association of ulcerative colitis and Takayasu's aortitis ?-
} report of a case

\author{
Hideki Ikenaga, Tohru Ogihara, Shigeru Iyori, Sen Kou, Hiroshi Yoshikawa ${ }^{1}$ and \\ Masashi Mikihiko Okura ${ }^{1}$
}

Department of Internal Medicine and ${ }^{1}$ Department of Cardiology, Hiratsuka City Hospital, Hiratsuka, Kanagawa 254, Japan.

\begin{abstract}
Summary: A case of a young Japanese woman with long-standing ulcerative colitis complicated by preinfarction angina due to Takayasu's aortitis is presented. Successful emergency aorto-coronary bypass operation was performed. Whether the association of these two diseases can be explained by a common mechanism is discussed.
\end{abstract}

\section{Introduction}

Since ulcerative colitis and Takayasu's aortitis are relatively uncommon disorders, the likelihood of their simultaneous occurrence is extremely small. Nevertheless, there have been several cases in which these two diseases have coexisted, suggesting some common pathophysiological background between them.

We describe here a case of a young Japanese woman with long-standing ulcerative colitis complicated by preinfarction angina due to Takayasu's aortitis. Successful emergency aorto-coronary bypass operation was performed. We discuss whether the combined occurrence of these two diseases can be explained by a common mechanism.

\section{Case report}

A 23 year old Japanese woman was admitted to Hiratsuka City Hospital, Kanagawa, Japan, in March 1988 , for treatment and evaluation of precordial pain precipitated by physical exertion and a positive double Master test. In 1963, when she was 8 years old, she developed refractory diarrhoea with blood and mucus. She was diagnosed as having ulcerative colitis by colonoscopy, colonic biopsy and barium enema examination, and was treated with salicylazosulphapyridine and prednisolone. In 1979, prednisolone was stopped, and she remained well until December 1987, when the precordial pain appeared. There was

Correspondence: Hideki Ikenaga, M.D.

Accepted: 28 April 1989 no history of smoking or use of oral contraceptives.

Figure 1 shows a colonic biopsy histology performed in April 1984. Although the typical "cryp abscess' is not seen, ulceration without granulomas of epithelioid cells confirmed the diagnosis of ulcerative colitis.

On examination, the pulses of all extremities were normal and the blood pressure was $126 / 70 \mathrm{mmHg}$ in both arms. A grade 2 systolic murmur was heard along the left sternal border. No vascular bruits were audible. The optic fundi were normal.

Laboratory findings were as follows: erythrocyte sedimentation rate $57 \mathrm{~mm} / \mathrm{h}$, C-reative protein $4+$, white cell count $8.7 \times 10^{9} / 1$ with a normal differential, haemoglobin $11.4 \mathrm{~g} / \mathrm{dl}$, haematocrit $35.6 \%$, platelets $54.0 \times 10^{10} / 1$, fasting glucose $117 \mathrm{mg} / \mathrm{dl}$, and the cholesterol $117 \mathrm{mg} / \mathrm{dl}$. Serum protein electrophoresis revealed polyclonal hypergammaglobulinaemia. Serum IgG, IgA, and IgM were $1310 \mathrm{mg} / \mathrm{dl}, 405 \mathrm{mg} / \mathrm{dl}$, and $164 \mathrm{mg} / \mathrm{dl}$, respectively. $\mathrm{C}_{3}$ and $\mathrm{C}_{4}$ were within the normal range. Anti-nuclear antibody test and serological test for syphilis were negative. Circulating immune complexes were not detected. The urine was normal and stool specimens were trace positive for occult blood and negative for ova of parasites.

On the eighth hospital day, cardiac catheterization was performed. Selective coronary angiograms disclosed severe narrowing of the ostia of both the left main and right coronary arteries. The remaining vessels were entirely normal in calibre (Figure 2).

Soon after examination, she complained of severe precordial pain and hypotension developed. Electro- 


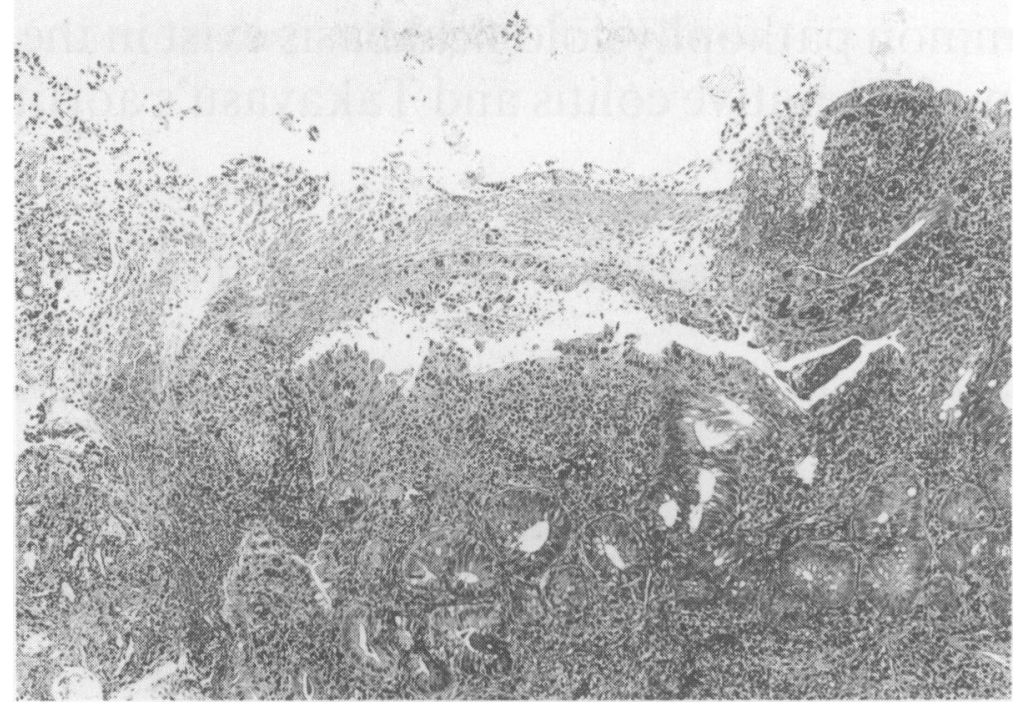

Figure 1 Biopsy of the sigmoid colon. Although the typical crypt abscess is not seen, ulceration covered by non-specific granulation tissue and the stromal inflammatory infiltrate composed of lymphocytes, plasma cells and neutrophils are compatible with the diagnosis of ulcerative colitis. There are no granulomas or epithelioid cells.
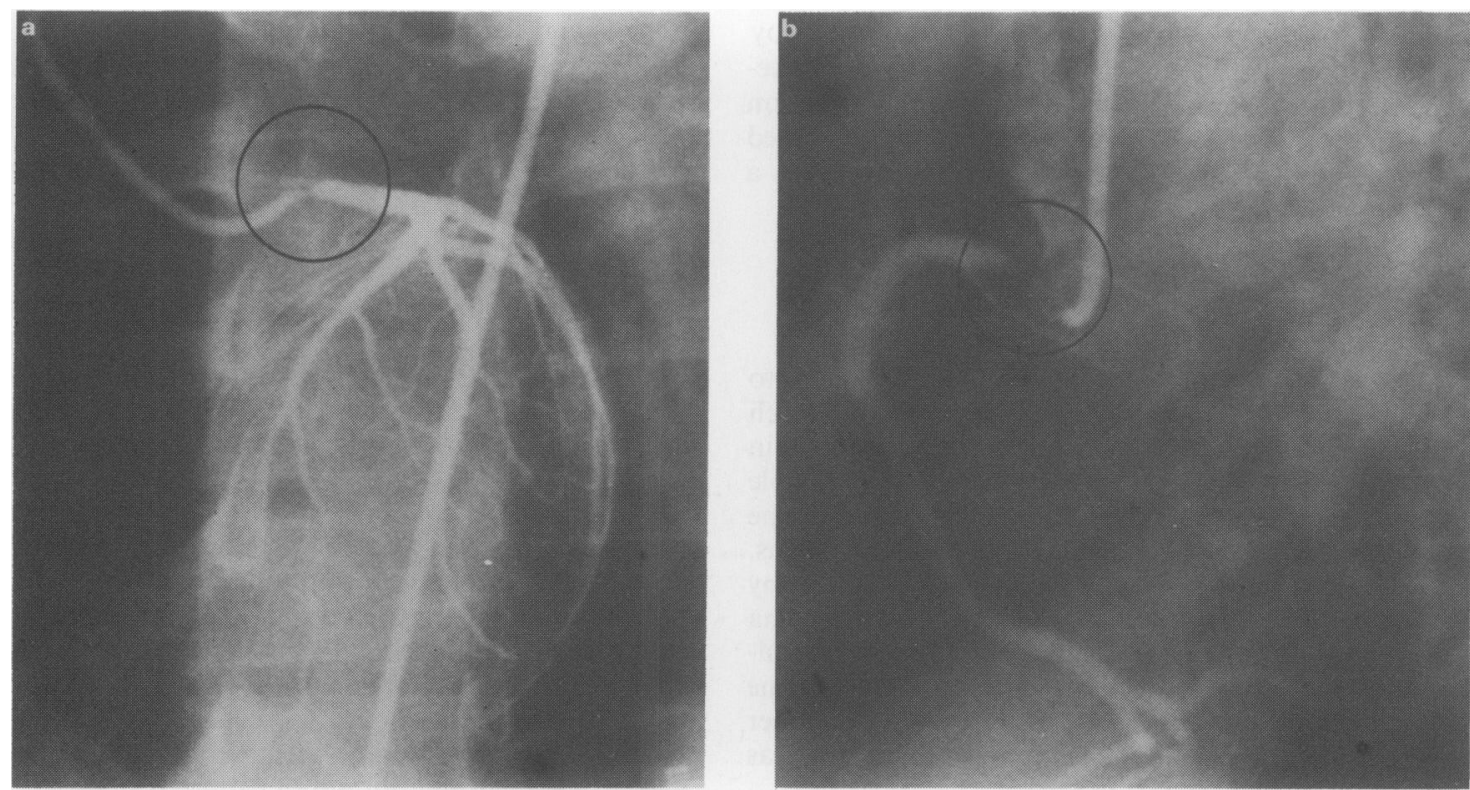

Figure 2 Selective coronary angiograms showing severe narrowing of the ostia of both the left main coronary artery (a) and the right coronary artery(b). 
cardiogram (ECG) showed ST segment elevation in leads II, III, and aVF, and ST segment depression in leads I, aVL, and V1 through V5. Since intensive medical therapy, including intra-aortic balloon counter pulsation, could not control the pain, emergency aorto-coronary bypass operation was performed.

At surgery, the aortic wall was thickened, oedematous, and had patchy sclerosing lesions. There was a tight adhesion between the ascending aorta and pulmonary artery trunk. Saphenous vein grafts from the aorta to the anterior descending artery and the right coronary artery were implanted, choosing the most inactive site for the anastomosis and a wide arteriotomy of $7 \mathrm{~mm}$.

A tiny piece of aortic tissue sampled at operation was examined microscopically. There was severe fibrosis in the media and adventitia, and the elastic fibres in the media were completely fragmented. Slight infiltrations of mononuclear cells, particularly lymphocytes, were seen around the vasa vasorum in the outer media and adventitia. The intima was fibrotic and thickened. All of these pathological findings were compatible with the diagnosis of Takayasu's aortitis.

She was discharged on the twentieth hospital day and has been followed up as an outpatient while undergoing administration of prednisolone. No recurrence has been observed to the end of 1988 .

\section{Discussion}

Takayasu's aortitis is a nonspecific inflammatory process of unknown aetiology affecting segmentally the aorta and its main branches. The incidence of coronary artery involvement has been reported to be approximately $10 \%^{1,2}$ and although uncommon, angina pectoris is one of the early symptoms, which include fever, fatigue, dizziness, headache, dyspnoea, and hypertension., ${ }^{3,4}$ Narrowing of the coronary arteries is produced mainly by contraction of the fibrotic media and adventitia in the aorta. Therefore, stenosis is characteristically limited to the ostia and proximal segments of the coronary arteries, ${ }^{3}$ as seen in our case.

Both inflammatory bowel disease and Takayasu's aortitis are relatively uncommon disorders. Since Soloway et al. ${ }^{5}$ first reported a case in 1970 , there have been 9 cases, including ours, of ulcerative colitis in association with Takayasu's aortitis. ${ }^{5-12}$ Six of the nine were Japanese, in whom the incidence of Takayasu's aortitis is relatively high. Crohn's disease is another major form of inflammatory bowel disease and 8 cases have been described in association with Takayasu's aortitis. ${ }^{13-20}$ According to Yassinger, ${ }^{14}$ assuming the incidence of Takayasu's aortitis to be 1 per one million persons, the chance of inflammatory bowel disease and Takayasu's aortitis occurring in the same patient is 1 in $\mathbf{1 0}$ trillion. The actual rate of association is more than ten thousand times higher than that of the estimated value, suggesting that some common pathophysiological background may exist.

Anti-colon antibodies and anti-aortic antibodies have been demonstrated in ulcerative colitis and Takayasu's aortitis, respectively, ${ }^{21-23}$ and a number of workers have directed their attention to the role of immune complexes. Lenhoff et al.$^{18}$ and Achar et al. ${ }^{10}$ proposed a hypothesis that immune complexes associated with Takayasu's aortitis may induce chronic colitis in certain susceptible individuals. Chapman et $a .^{8}{ }^{8}$ noted the possibility that immune complexes absorbed from the diseased colon might induce vasculitis. Table I summarizes the reported cases with both Takayasu's aortitis and ulcerative colitis which have occurred in either sequence. Neither circulating immune complexes nor depletion of complement has been detected. We did not find these serological abnormalities either, and in our case, the onset of ulcerative colitis preceded that of Takayasu's aortitis by as long as 15 years. Therefore, it seems highly

Table I Clinical findings of 9 patients with aortitis and ulcerative colitis (UC)

\begin{tabular}{|c|c|c|c|c|c|c|c|}
\hline \multicolumn{2}{|l|}{ Reference and year } & $A g e^{*}$ & Sex & \multicolumn{2}{|c|}{$\begin{array}{c}\text { Preceding disease } \\
\text { \& years }\end{array}$} & \multirow{2}{*}{$\frac{c-I C \dagger}{?}$} & \multirow{2}{*}{$\frac{A N A \ddagger}{(-)}$} \\
\hline Soloway et al. ${ }^{5}$ & 1970 & 33 & $\mathrm{~F}$ & UC & 2 years & & \\
\hline Sugishita et al. ${ }^{6}$ & 1973 & 20 & $\mathbf{F}$ & Aortitis & 2 years & $?$ & $(-)$ \\
\hline Tsuchiya et al. ${ }^{7}$ & 1976 & 20 & $\mathrm{~F}$ & UC & 4 years & $?$ & $(-)$ \\
\hline Chapman et al. ${ }^{8}$ & 1978 & 17 & $\mathrm{~F}$ & UC & 2 years & $(-)$ & $(-)$ \\
\hline Miwa et al. ${ }^{9}$ & 1979 & 40 & $\mathbf{F}$ & Aortitis & 20 years & $?$ & $(-)$ \\
\hline Achar et al..$^{10}$ & 1986 & 35 & $\mathbf{F}$ & UC & 1 years & $(-)$ & $(-)$ \\
\hline Yamaguchi et al. ${ }^{11}$ & 1988 & 19 & $\mathbf{M}$ & UC & 9 years & $?$ & $?$ \\
\hline Ichikawa et al. ${ }^{12}$ & 1988 & 12 & $\mathbf{F}$ & UC & 10 years & $(-)$ & $(-)$ \\
\hline Present case & & 8 & $\mathbf{F}$ & UC & 15 years & $(-)$ & $(-)$ \\
\hline
\end{tabular}

*Age at the time when first symptom appeared; †circulating immune complex;

$\ddagger$ antinuclear antibodies. 
improbable that circulating immune complexes might have induced both colitis and vasculitis.

Nevertheless, this does not exclude the possibility that some immunological defect, other than one of immune complexes, might play an important role in the pathogenesis of the two diseases. One possibility is that certain genes may allow augumented antibody responses, as well as auto-antibodies, following a variety of stimuli, and the anti-aortic and anti-colon antibodies are produced independently. Tsuchiya $e t$

\section{References}

1. Nasu, T. Autopsy study of aortitis syndrome. Report by the Ministry of Health and Welfare, Japan, 1975, p111 (in Japanese).

2. Lupi-Herrera, E., Sanchez-Torres, G., Marcushamer, J., Mispireta, J., Horwitz, S. \& Vela, J.E. Takayasu's arteritis. Clinical study of 107 cases. Am Heart J 1977, 93: 94-103.

3. Cipriano, P.R., Silverman, J.F., Perlroth, M.G., Griepp, R.B. \& Wexler, L. Coronary arterial narrowing in Takayasu's aortitis. Am J Cardiol 1977, 39: 744-750.

4. Inanami, H., Asaka, T., Yoshida, K. et al. Coronary ostial stenosis due to aortitis syndrome (Takayasu's arteritis) in a young female: Report of a case. J Cardiogr 1983, 13: 761-768.

5. Soloway, M., Moir, T.W. \& Linton, D.S. Takayasu's arteritis. Report of a case with unusual findings. $\mathrm{Am} \mathrm{J}$ Cardiol 1970, 25: 258-263.

6. Sugishita, T., Kasai, K., Kikuchi, T. et al. A case of aortitis syndrome associated with ulcerative colitis. Naika 1973, 31: 517-521 (in Japanese).

7. Tsuchiya, M., Okazaki, I., Mizuno, O., Asakura, H. \& Hiramatsu, K. Aortitis syndrome associated with ulcerative colitis. Vascular Surg 1976, 10: 176-181.

8. Chapman, R., Dawe, C., Whorwell, P.J. \& Wright, R. Ulcerative colitis in association with Takayasu's disease. Am J Dig Dis 1978, 23: 660-662.

9. Miwa, Y., Nagasako, K., Sasaki, H. et al. Aortitis syndrome associated with ulcerative colitis: Report of a case. Gastroenterol Jap 1979, 14: 492-495.

10. Achar, K.N. \& Al-Nakib, B. Takayasu's arteritis and ulcerative colitis. Am J Gastroenterol 1986, 81: 1215-1217.

11. Yamaguchi, A., Kitamura, N., Otaki, M., Minoji, T., Tamura, H. \& Kurata, A. A case of Bentall's operation for annulo aortic ectasia complicated with ulcerative colitis and aortitis syndrome. Nippon Kyobu Geka Gakkai Zasshi 1988, 36: 578-582 (in Japanese). $a l .^{7}$ focused their attention on cellular immunity, but this was not examined in our case.

At present, the simultaneous occurrence of $\frac{.}{}$ Takayasu's aortitis and ulcerative colitis is extremely $\overrightarrow{\vec{F}}$ rare; the aetiologies of the two diseases remain obs $-\frac{-}{-}$ cure. Further studies will be required to clarify therelationship between these two diseases, especially in $\overline{\bar{n}}$ terms of immunological background, including gene expression.

12. Ichikawa, M., Onizuka, T., Ichikawa, K., Ohama, A., Takahara, O. \& Hoshino, H. A case of ulcerative colitisassociated with Takayasu's arteritis. Nippon Shokakibyoo Gakkai Zasshi 1988, 85: 1690-1693 (in Japanese).

13. Bigot, R., Gateau, P., Chermet, J., Doyon, D., \& Monnier, J.P. Ileite terminale et maladie de Takayasu. Ann Radiol (Paris) 1973, 16: 767-771.

14. Yassinger, S., Adelman, R., Cantor, D., Halstead, C.H.은 \& Bolt, R.J. Association of inflammatory bowel disease_and large vascular lesions. Gastroenterology 1976, 71: 844-846.

15. Friedman, C.J. \& Tegtmeyer, C.J. Crohn's diseaseo associated with Takayasu's arteritis. Dig Dis Sci 19\%, 24: 954-958.

16. Owyang, C., Miller, L.J., Lie, J.T. \& Fleming, C $\mathbf{R}$. Takayasu's arteritis in Crohn's disease. Gastroenterolo 1979, 76: 825-828.

17. Beau, B., Colasse, W., Le Bihan, G. \& Bourreille, J. Association d'une maladie de Takayasu et d'une colite inflammatoire. Sem Hop Paris 1980, 56: 1841-1845.

18. Lenhoff, S.J. \& Mee, A.S. Crohn's disease of the colon $\bar{\varnothing}$ with Takayasu's arteritis. Postgrad Med J 1982, 58: 386-389.

19. Gray, R. \& Newman, H. Arteritis associated with Crohn's disease. Gastrointest Radiol 1983, 8: 53-55.

20. Talbot, R.W., Heppell, J., Dozois, R.R. \& Beart, R.W. Vascular complications of inflammatory bowel disease. Mayo Clin Proc 1986, 61: 140-145.

21. Lagercrantz, R., Hammarstorm, S., Perlmann, P. \& Gustafsson, B.E. Immunological studies in ulcerative 3 . colitis. Origin of autoantibodies. J Exp Med 1968, 128: $1339-1352$

22. Broberger, O.\& Perlmann, P. Autoantibodies in human ulcerative colitis. J Exp Med 1959, 110: 657-674.

23. Ito, I., Saito, Y.\& Nonaka, Y. Immunological aspects of $D$ aortitis syndrome. Jpn Circ J 1975, 39: 459-462. 